\title{
Computer processing of cardiac catheterization data
}

\author{
J. P. Blackburn, E. A. Christopher, ${ }^{1}$ L. Cillie, D. C. Deuchar, P. R. Fleming, G. A. H. Miller, \\ and D. G. Morgan ${ }^{2}$ \\ From the Medical Computer Centre, the Department of Clinical Measurement and the Medical Unit, West- \\ minster Hospital; the Cardiac Department, Brompton Hospital; and the Cardiac Department, Guy's Hospital, \\ London
}

A set of forms suitable for digital computer processing has been designed for manual data entry by the investigator after cardiac catheterization. The computer produces the catheterization report and a data bank is being built up for information retrieval and statistical analysis. A number of hospitals have been using the system since 1970 and the records of over 1000 cases are collected annually.

The process of extracting information about a series of cases investigated by cardiac catheterization or of analysing the work of one cardiac centre is very time consuming when this has to be done by hand, whereas data stored in a computer are easily available and may be analysed by complex statistical methods. Such analyses may then point to the need for improvements in methods of investigation or lead to increased diagnostic accuracy (Wallace and Rosati, 1973). Partial automation of a cardiac catheterization data retrieval system and its trial in a number of hospitals was, therefore, considered worth while. A method for on-line analysis of signals obtained during cardiac catheterization has been described (Henry et al., 1968), but it was decided that a fully automated system was not justified at this stage.

A simple set of forms was produced so that data could be entered directly by the cardiologist after the investigation and the forms sent to the computer centre for processing. Hospitals wishing to use the system did not have to buy expensive equipment or modify their cardiac catheterization procedure appreciably.

It was considered important that the work load on the cardiologist should not be increased and that the computer must produce an acceptable cardiac catheterization report. In addition, a copy of the data entry form had to be easily interpretable by the

Received 8 April 1974.

${ }^{1}$ Present address: Computer Instrumentation Ltd., School Lane, Chandlers Ford, Hants.

2 Present address: Department of Health \& Social Security, Ray House, 6 St. Andrew's Street, London EC 4A. clinician, so that it could be used until the computer report was available.

\section{Method}

Careful initial planning of the service with agreement between the hospitals concerned on certain points of technique, the scope of the computer processing, and the format of the catheter report have been essential features contributing largely to the success of this project. All participants agreed to standardize their manometry using midchest as the zero reference and to time events by using elapsed time from the start of the operation. The layout of the data forms, the extent of the information to be included, and the method of presenting the results were all discussed in detail before the forms were designed and printed.

The form consists of four double sheets of pressure sensitive NCR paper illustrated in Fig. I a and b, 2, 3, and 4. The cardiologist fills in and retains the top copies as temporary reports and the information is duplicated automatically on the lower copies which are specially designed so that the data can be easily coded on 80 column IBM cards. These copies are sent to the computer centre for coding, and processing is carried out on an IBM 1800 computer at the Medical Computer Centre, Westminster Hospital. The data are stored on magnetic tape for subsequent retrieval and analysis.

All information is entered in numerical form in fixed format except for the patient's name, number, and diagnosis. In addition, a fifth sheet (not illustrated) is available for entering information about the results of angiographic studies or special investigations (such as intracardiac phonocardiography or electrocardiography). This information is not coded, but the computer can identify those patients on whom special studies have been performed using the 'other procedures' codes on sheet 2 , so that the cardiologist can refer to the original records easily when required. 
CARDIAC CATHETERISATION REPORT

SHEET 1 HOSPITAL

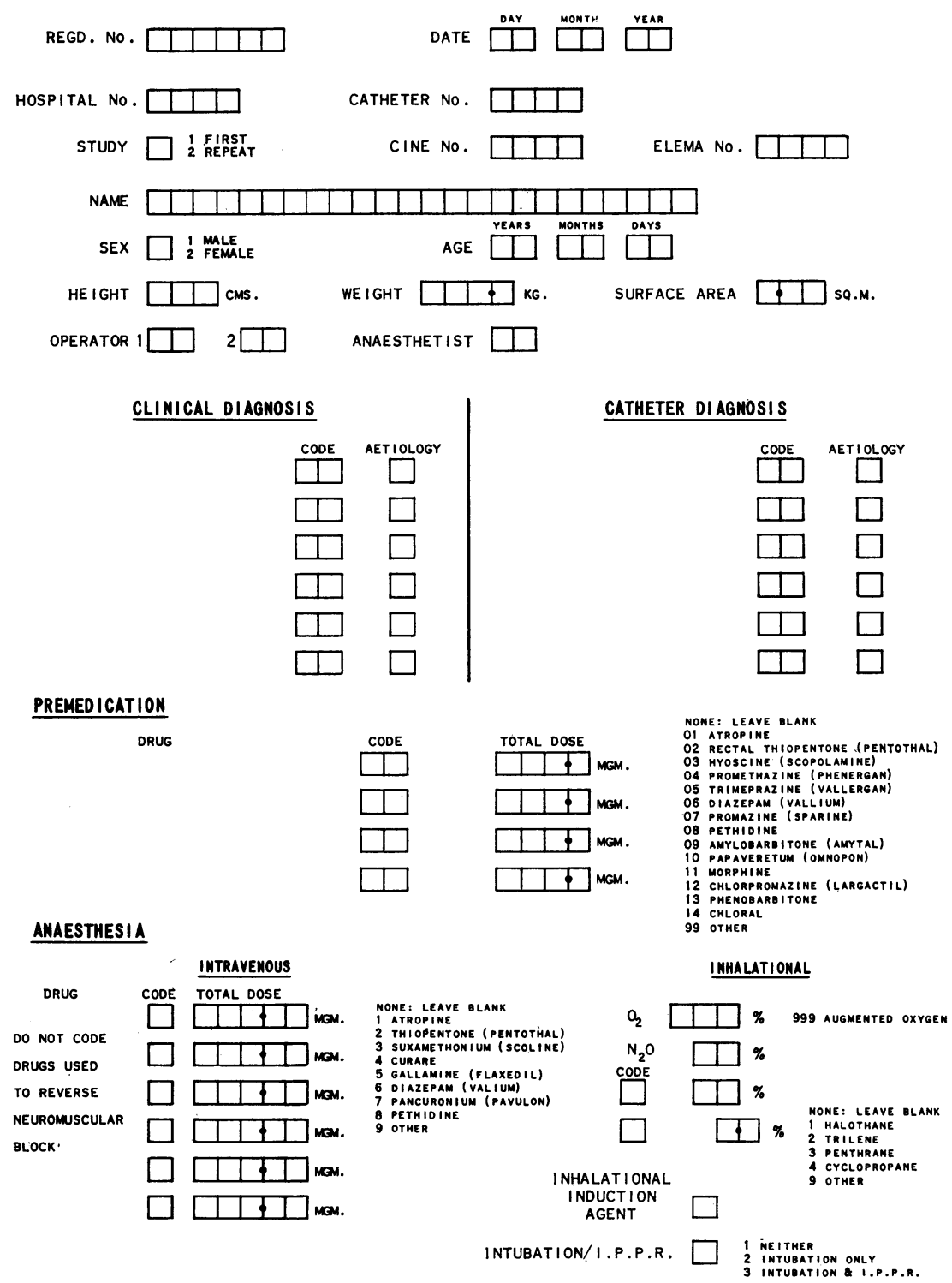

FIG. I, a and b Upper and lower copies of the first sheet of the cardiac catheterization data entry form. The top copy is retained by the cardiologist and the lower copy sent to the computer centre for processing. 
SHEET 1
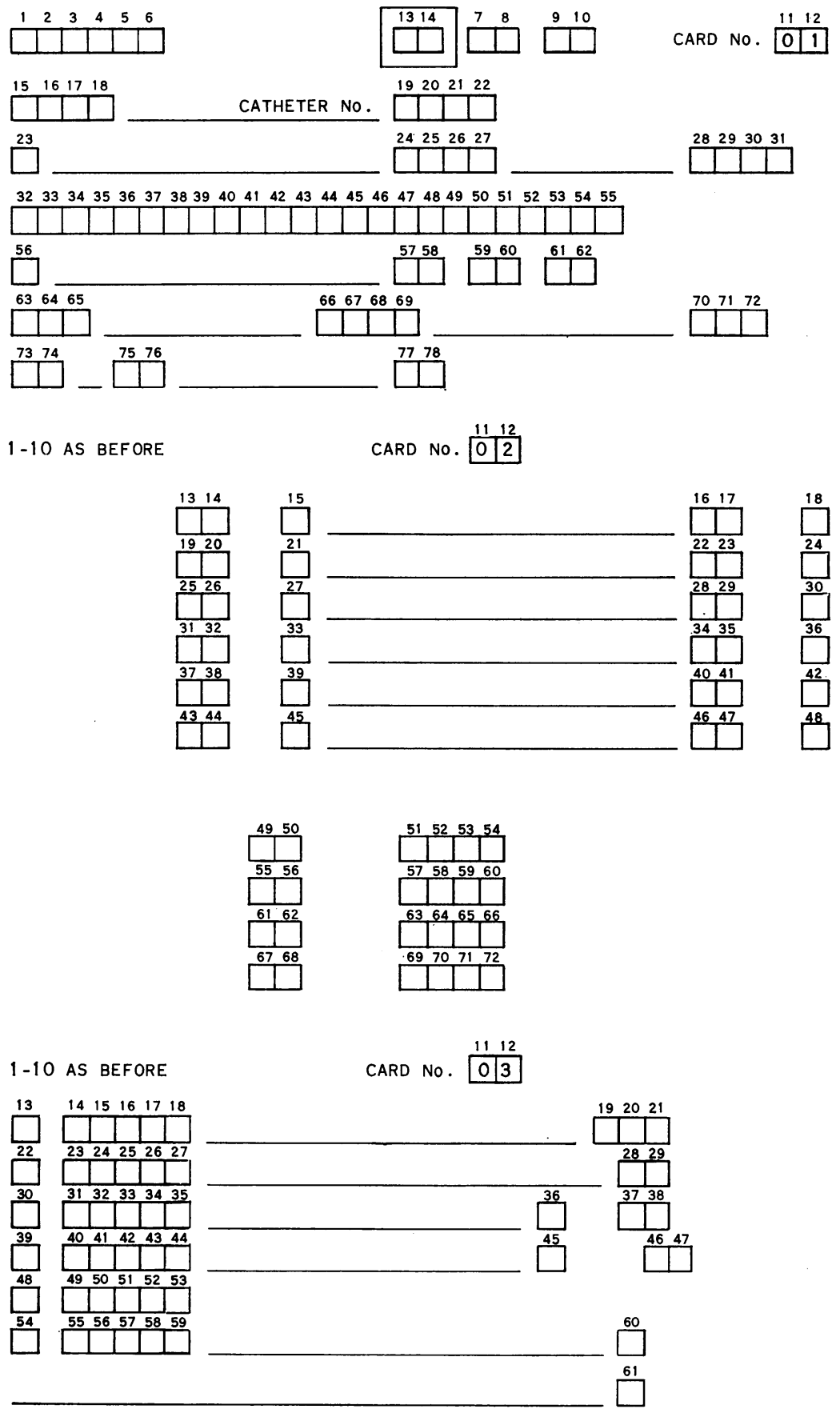

CARD 3 CONTINUED ON SHEET 2

FIG. Ib 
CATHETER NO

$\square$

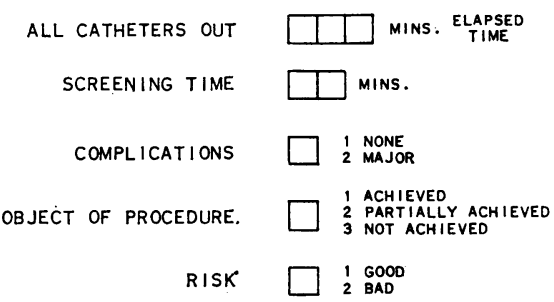

OTHER PROCEDURES

OTHER PROCEDURES

1 INTRACARDiac PHONO.

2 INTRACARDIAC E.C.G.

3 INTRACARDIAC MANOMETRY

4 INDICATOR DILUTION CURVES

5 FLOW GUIDED CATHETERS

9 OTHER

PROCEDURE

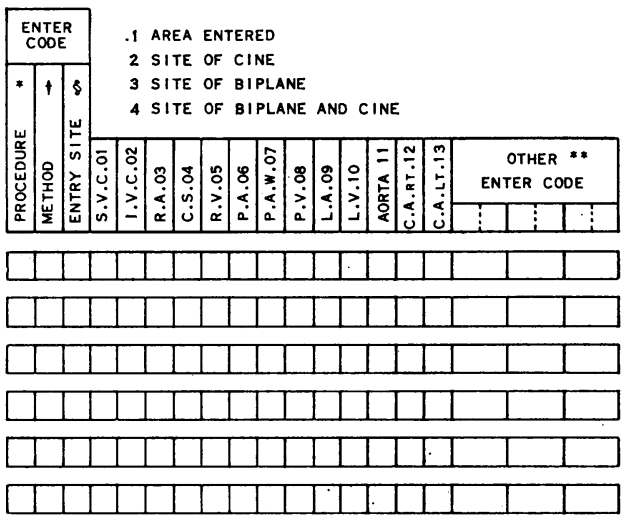

X-RAY PARTICULARS

\begin{tabular}{|c|c|c|c|c|c|c|c|c|}
\hline \multirow{2}{*}{ 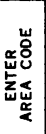 } & \multicolumn{2}{|c|}{$\begin{array}{l}\text { CONTRAS } \\
\text { MEDIUM } \\
\end{array}$} & \multirow{2}{*}{ 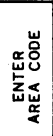 } & \multicolumn{2}{|c|}{\begin{tabular}{|c|} 
CONTRAST \\
MEDIUM \\
It
\end{tabular}} & \multirow{2}{*}{ 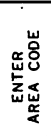 } & \multicolumn{2}{|c|}{$\begin{array}{l}\text { CONTRAST } \\
\text { MED IUM } \\
\end{array}$} \\
\hline & $\mid$ & 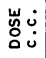 & & . & نٌ & & |w & نُّن \\
\hline
\end{tabular}

\begin{tabular}{|l|l|l|l|l|l|l|l|l|}
\hline$:$ & & & & & $\vdots$ & & &
\end{tabular}

CODES

\begin{tabular}{|c|c|}
\hline PROCEDURE * & METHOO + \\
\hline $\begin{array}{ll}1 & \text { RT. HEART } \\
2 & \text { TRANS SEPTAL } \\
3 & \text { L.V. PUNCTURE } \\
4 & \text { RETROGRADE ARTERIAL } \\
5 & \text { INOWELLING } \\
\text { ARER IAL NEEDLE } \\
6 \text { SUPRASTERNAL } \\
\text { PUNCTURE } \\
7 \text { POSTERIOR THORACIC } \\
\text { (L.A.) } \\
8 \text { ATRIAL SEPTOSTOMY } \\
9 \text { OTHER }\end{array}$ & $\begin{array}{l}1 \text { PERCUTANEOUS } \\
2 \text { CUT -DOWN }\end{array}$ \\
\hline CONTRAST MEDIUM It & \\
\hline $\begin{array}{l}1 \text { HYPAQUE } 45 \% \\
2 \text { HYPAOUE } 65 \% \\
3 \text { HYPAOUE } 85 \% \\
4 \text { TRIOSIL } 75 \% \\
5 \text { UROGRAFIN } 76 \\
6 \text { CONRAY } 280 \\
7 \text { CONRAY } 420 \\
8 \text { CARD IOCONRAY } \\
9 \text { OTHER }\end{array}$ & \\
\hline
\end{tabular}

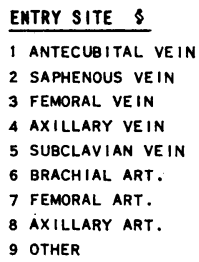

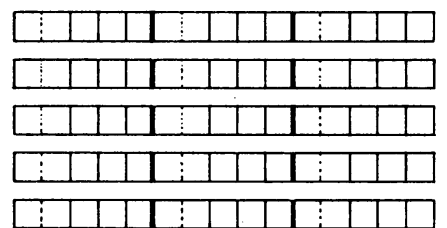

OTHER AREAS EMTERED **

14 LT. S.V.C.

i5 INNOMINATE VEIN

16 COMMON ANOMALOUS P.V.

17 Rr. ANOMALOUS P.V.

$18 \mathrm{LT}$. ANOMALOUS P.V.

19 P.D.A.

20 COMMON (SINGLE) VENTRICLE

21 PERSISTENT TRUNCUS

22 WEDGE P.V.

23 RT. P.A.

24 LT. P.A.

25 SYSTEMIC ART. RT. ARM

26 SYSTEMIC ART. LT. ARM

27 SYSTEMIC ART. RT. LEG

28 SYSTEMIC ART. LT. LEG

29 AZYGOS VEIN

FIG. 2, 3, 4. Top copies of the other sheets used for recording details of the procedure and results. 


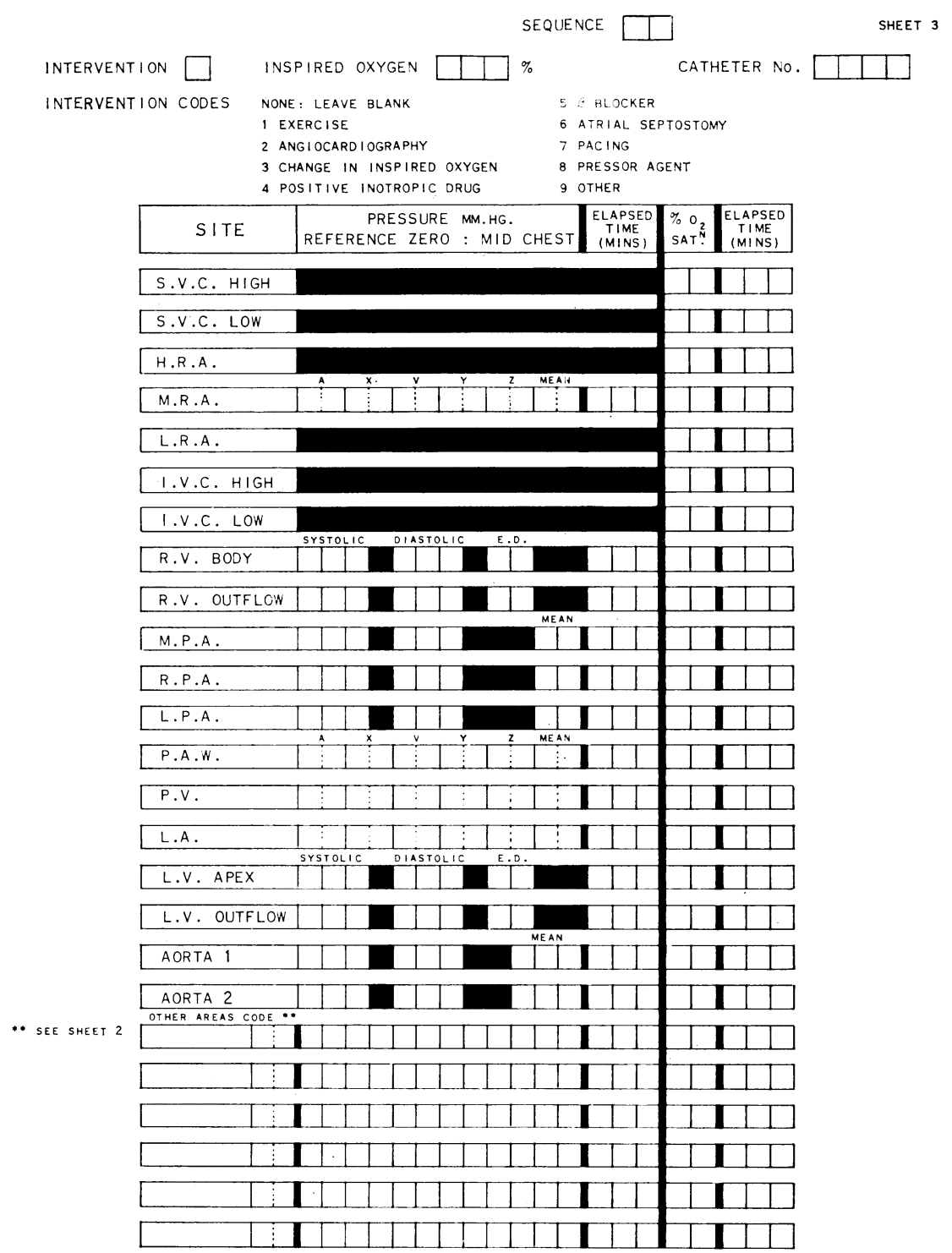

SAMPLES TO BE USED FOR FLOW CALCULATION

SYSTEMIC (MIXED) VENOUS SATURATION

SYSTEMIC ARTERIAL SATURATION

PULMONARY VENOUS SATURATION

PULMONARY ARTERIAL SATURATION $\square \%$

$\square \%$

$\square \%$

$\square \%$

$$
\begin{aligned}
& \text { CONTENT } \square \square \text { c.c./100 c.c. } \\
& \text { CONTENT } \square \square \text { c.c. } / 100 \text { c.c. } \\
& \text { CONTENT } \square \square \text { c.c. } / 100 \text { c.c. } \\
& \text { CONTENT } \square \square \text { c.c. } 1100 \text { c.c. }
\end{aligned}
$$

FIG. 3 

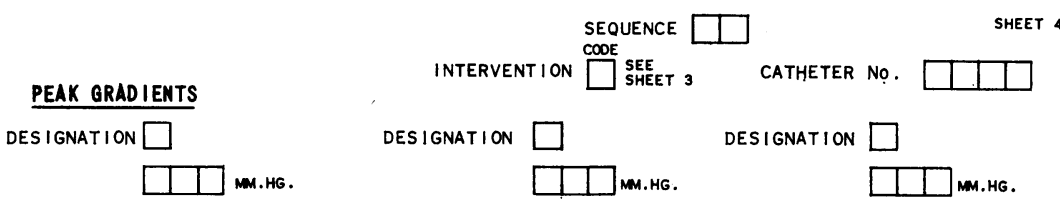

\section{MEAN GRADIENTS}

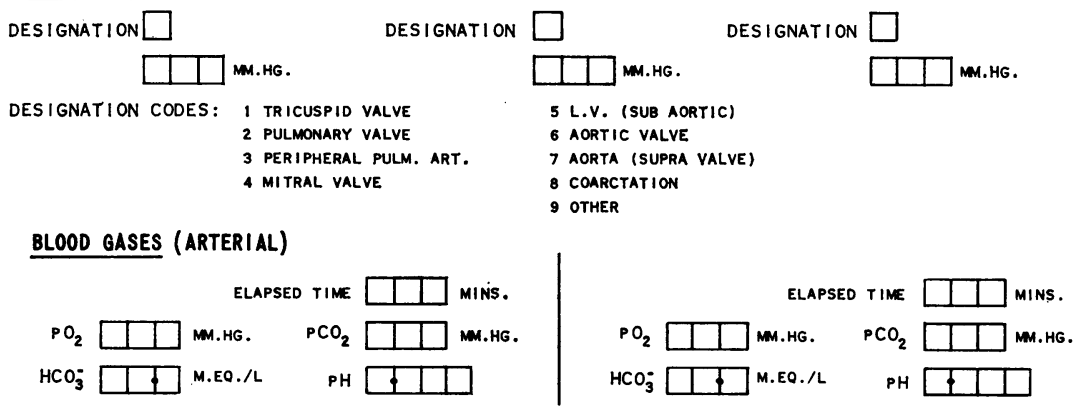

DATA FOR FLOW CALCULATIONS

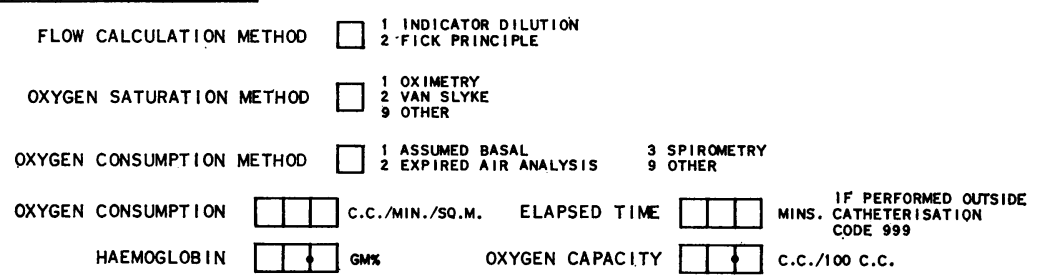

\section{EXPIRED AIR AMALYSIS}

TOTAL VOL. EXPIRED AIR $\square \square$ L.. DURATION OF COLLECTION $\square \square$ MINS.

OXYGEN IN EXPIRED AIR $\square\left[\begin{array}{l}\hline \\ \text { O }\end{array} \quad \mathrm{CO}_{2}\right.$ IN EXPIRED AIR $\square \square$ \%

ROOM TEMPERATURE $\square \square{ }^{\circ} \mathrm{C} \quad$ BAROMETRIC PRESS. $\square \square \square$ M..HG.

\section{CALCULATI ONS}

FLOWS

PULMONARY (Q̈P) $\square \square \square$ L.MIN./SO.M.

SYSTEMIC (Q́S) $\square \square \square$ L.MMiN./SO.M.

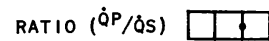

EFFECTIVE PULM. $\square \square \square$ L.MIN./SO.M.

SHUNTS

LEFT TO RIGHT $\square \square$ L.MIN./SO.M.

RIGHT TO LEFT $\square \square$ L.MIN./SO.M.

\section{RESISTAMCES}

TOTAL PULMONARY $\left(R_{p}\right)$. $\square$. UNITS $\times$ SO.M.

PULMONARY ARTER IOLAR $\left(R_{\mathrm{Pa}}\right) \square \square$ UNITS $\times$ SO.M.

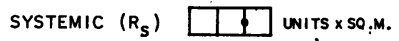
RATIO $\left(R_{P} / R_{S}\right) \quad \square \quad \square$

FIG. 4 
TABLE I Aetiological and diagnostic codes

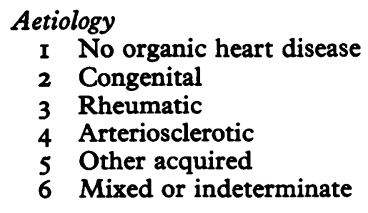

\begin{tabular}{|c|c|c|c|c|c|}
\hline & \multicolumn{2}{|l|}{ Presence } & \multicolumn{3}{|c|}{ Severity of condition } \\
\hline & Diagnosis & $\begin{array}{l}\text { Qucry } \\
\text { Diagnosis }\end{array}$ & Mild & Severe & $\begin{array}{l}\text { Query } \\
\text { severity }\end{array}$ \\
\hline No anatomical lesion & $\mathbf{I}$ & $\mathrm{oB}$ & oQ & AI & Pr \\
\hline Atrial septal defect, secundum & 2 & oC & OR & A2 & $\mathbf{P}_{2}$ \\
\hline Atrial septal defect, sinus venosus defect & 3 & oD & os & A3 & $\mathbf{P}_{3}$ \\
\hline Endocardial cushion defect & 4 & $\mathrm{oE}$ & OT & $\mathrm{A}_{4}$ & $\mathbf{P}_{4}$ \\
\hline Common atrium & 5 & oF & oU & A5 & $P_{5}$ \\
\hline Total anomalous pulmonary venous return & 6 & oG & oV & A6 & P6 \\
\hline Hemianomalous pulmonary venous return & 7 & $\mathrm{oH}$ & oW & A7 & $\mathrm{P}_{7}$ \\
\hline Left ventricle to right atrial fistula: Gerbode defect & 8 & oI & oX & A8 & P8 \\
\hline Ventricular septal defect & 9 & oJ & oY & A9 & $\mathrm{Pg}$ \\
\hline Ventricular septal defect with pulmonary stenosis & 10 & IA & IP & Bo & Qo \\
\hline Ventricular septal defect with pulmonary atresia & II & IB & IQ & BI & QI \\
\hline Common ventricle & 12 & IC & $\mathbf{I R}$ & $\mathbf{B 2}$ & Q2 \\
\hline Tricuspid atresia & 13 & ID & IS & B3 & Q3 \\
\hline Ebstein's anomaly of tricuspid valve & 14 & IE & IT & B4 & Q4 \\
\hline Hypoplastic right ventricle and Uhl's syndrome & 15 & IF & $\mathrm{IU}$ & B5 & Q5 \\
\hline Pulmonary stenosis, valvar & 16 & IG & IV & B6 & Q6 \\
\hline Pulmonary stenosis, infundibular & 17 & IH & $\mathbf{I W}$ & B7 & Q7 \\
\hline Pulmonary atresia, with intact ventricular septum & 18 & II & $\mathbf{I X}$ & B8 & Q8 \\
\hline Anomalous systemic venous return to left atrium & I9 & $\mathbf{I J}$ & $\mathbf{I Y}$ & B9 & Q9 \\
\hline Anomalies of systemic venous return to right atrium & 20 & $\mathbf{2 A}$ & $\mathbf{2 P}$ & Co & Ro \\
\hline Persistent truncus arteriosus & $2 \mathbf{I}$ & $\mathbf{2 B}$ & $2 Q$ & $\mathbf{C I}_{\mathbf{I}}$ & $\mathbf{R I}$ \\
\hline Aortico-pulmonary window & 22 & $2 \mathrm{C}$ & $2 \mathbf{R}$ & $\mathbf{C}_{2}$ & $\mathbf{R 2}$ \\
\hline Persistent ductus arterious & 23 & $2 \mathrm{D}$ & $2 S$ & $\mathrm{C}_{3}$ & $\mathbf{R}_{3}$ \\
\hline Systemic-pulmonary arterial communication & 24 & $2 \mathrm{E}$ & $2 \mathrm{~T}$ & $\mathrm{C}_{4}$ & $\mathbf{R}_{4}$ \\
\hline Dextro-transposition & 25 & $\mathbf{2 F}$ & $2 \mathrm{U}$ & $\mathrm{C}_{5}$ & $\mathbf{R 5}$ \\
\hline Laevo-transposition & 26 & $2 \mathrm{G}$ & $2 \mathrm{~V}$ & C6 & R6 \\
\hline Partial transposition & 27 & $\mathbf{2 H}$ & $2 W$ & $\mathrm{C}_{7}$ & R7 \\
\hline Dextrocardia & 28 & 2I & $2 \mathrm{X}$ & C8 & R8 \\
\hline Isolated laevocardia & 29 & $2 \mathrm{~J}$ & $2 \mathrm{Y}$ & C9 & R9 \\
\hline Hypoplastic left heart syndrome & 30 & $3 \mathrm{~A}$ & $3 \mathbf{P}$ & Do & Só \\
\hline Anomalous origin of coronary arteries & $3 \mathbf{I}$ & $3 \mathbf{B}$ & $3 Q$ & $\bar{D}_{\mathbf{I}}$ & SI \\
\hline Infantile coronary artery disease & 32 & $3 \mathrm{C}$ & $\mathbf{3} \mathbf{R}$ & $\mathrm{D}_{2}$ & S2 \\
\hline Coronary arteriovenous fistula & 33 & $3 \mathrm{D}$ & $3 S$ & $\mathrm{D}_{3}$ & $S_{3}$ \\
\hline Ruptured sinus of Valsalva & 34 & $3 \mathrm{E}$ & $3 \mathrm{~T}$ & $\mathrm{D}_{4}$ & $\mathrm{~S}_{4}$ \\
\hline Systemic arteriovenous fistula & 35 & $3 F$ & $3 U$ & D5 & S5 \\
\hline Pulmonary arteriovenous fistula & 36 & $3 G$ & $3 \mathrm{~V}$ & D6 & S6 \\
\hline Coarctation & 37 & $3 \mathrm{H}$ & $3 W$ & $\mathrm{D}_{7}$ & S7 \\
\hline Congenital interruption of aortic arch & 38 & $3 \mathrm{I}$ & $3 \mathbf{x}$ & D8 & S8 \\
\hline Other aortic arch anomalies & 39 & $3 \mathrm{~J}$ & $3 Y$ & D9 & S9 \\
\hline Cor triatriatum & 40 & $4 \mathrm{~A}$ & $4 \mathrm{P}$ & Eo & To \\
\hline Stenosis or thrombosis of pulmonary veins & $4 I$ & 4B & $4 Q$ & $\vec{E}_{\mathbf{I}}$ & Tr \\
\hline Peripheral pulmonary artery stenosis & 42 & $4 \mathrm{C}$ & $4 \mathbf{R}$ & $\mathbf{E}_{2}$ & $\mathbf{T}_{2}$ \\
\hline Anomalies of pulmonary arteries & 43 & $4 \mathrm{D}$ & $4 \mathrm{~S}$ & $\mathbf{E}_{3}$ & $\mathbf{T}_{3}$ \\
\hline Primary pulmonary hypertension & 44 & $4 \mathrm{E}$ & $4 \mathrm{~T}$ & $\mathbf{E}_{4}$ & $\mathrm{~T}_{4}$ \\
\hline Cor pulmonale & 45 & $4 F$ & $4 U$ & $\mathbf{E}_{5}$ & $\mathbf{T}_{5}$ \\
\hline Thromboembolic pulmonary hypertension & 46 & $4 G$ & $4 \mathrm{~V}$ & E6 & T6 \\
\hline Pulmonary embolism & 47 & $4 \mathrm{H}$ & 4W & E7 & $\mathrm{T}_{7}$ \\
\hline Pulmonary hypertension & 48 & $4 \mathrm{I}$ & $4 \mathrm{X}$ & E8 & T8 \\
\hline Primary myocardial disease & 49 & $4 \mathrm{~J}$ & $4 \mathrm{Y}$ & E9 & T9 \\
\hline Primary endocardial disease & 50 & $5 \mathrm{~A}$ & $5 P$ & Fo & Uo \\
\hline Diverticulum of left ventricle & 51 & $5 B$ & $5 Q$ & $F_{I}$ & UI \\
\hline Tricuspid stenosis & 52 & $5 \mathrm{C}$ & $5 \mathbf{R}$ & $F_{2}$ & $\mathrm{U}_{2}$ \\
\hline Tricuspid incompetence & 53 & $5 \mathrm{D}$ & $5 S$ & $F_{3}$ & $\mathrm{U}_{3}$ \\
\hline Mitral stenosis & 54 & $5 E$ & $5 \mathrm{~T}$ & $\mathrm{~F}_{4}$ & $\mathrm{U}_{4}$ \\
\hline
\end{tabular}


TABLE I-continued

\begin{tabular}{|c|c|c|c|c|c|}
\hline & \multicolumn{2}{|l|}{ Presence } & \multicolumn{3}{|c|}{ Severity of condition } \\
\hline & Diagnosis & $\begin{array}{l}\text { Query } \\
\text { diagnosis }\end{array}$ & Mild & Severe & $\begin{array}{l}\text { Query } \\
\text { severity }\end{array}$ \\
\hline $\begin{array}{l}\text { Mitral incompetence } \\
\text { Mitral stenosis and incompetence } \\
\text { Pulmonary incompetence } \\
\text { Aortic stenosis-supravalvar } \\
\text { Aortic stenosis-valvar } \\
\text { Aortic stenosis-subvalvar } \\
\text { Aortic incompetence } \\
\text { Aortic stenosis (valvar) and incompetence } \\
\text { Aortic aneurysm } \\
\text { Dissection of aorta } \\
\text { Hypertrophic obstructive cardiomyopathy } \\
\text { Other cardiomyopathies } \\
\text { Coronary artery disease } \\
\text { Disease of right coronary artery } \\
\text { Disease of anterior descending coronary artery } \\
\text { Disease of circumflex coronary artery } \\
\text { Myocardial infarction } \\
\text { Ventricular aneurysm } \\
\text { Pericardial disease } \\
\text { Cardiac myxoma } \\
\text { Cardiac tumour } \\
\text { Heart block } \\
\text { Atrial fibrillation } \\
\text { Other arrhythmias } \\
\text { Systemic hypertension } \\
\text { Postoperative study } \\
\text { Other } \\
\text { Visceral situs-solitus } \\
\text { Visceral situs-inversus } \\
\text { Visceral situs-indeterminate }\end{array}$ & $\begin{array}{l}55 \\
56 \\
57 \\
58 \\
59 \\
60 \\
61 \\
62 \\
63 \\
64 \\
65 \\
66 \\
67 \\
68 \\
69 \\
70 \\
71 \\
72 \\
73 \\
74 \\
75 \\
76 \\
77 \\
78 \\
79 \\
80 \\
81 \\
82 \\
83 \\
84\end{array}$ & $\begin{array}{l}5 \mathrm{~F} \\
5 \mathrm{G} \\
5 \mathrm{H} \\
5 \mathrm{I} \\
5 \mathrm{~J} \\
6 \mathrm{~A} \\
6 \mathrm{~B} \\
6 \mathrm{C} \\
6 \mathrm{D} \\
6 \mathrm{E} \\
6 \mathrm{~F} \\
6 \mathrm{G} \\
6 \mathrm{H} \\
6 \mathrm{I} \\
6 \mathrm{~J} \\
7 \mathrm{~A} \\
7 \mathrm{~B} \\
7 \mathrm{C} \\
7 \mathrm{D} \\
7 \mathrm{E} \\
7 \mathrm{~F} \\
7 \mathrm{G} \\
7 \mathrm{H} \\
7 \mathrm{I} \\
7 \mathrm{~J} \\
8 \mathrm{~A} \\
8 \mathrm{~B} \\
8 \mathrm{C} \\
8 \mathrm{D} \\
8 \mathrm{E}\end{array}$ & $\begin{array}{l}5 \mathrm{U} \\
5 \mathrm{~V} \\
5 \mathrm{~W} \\
5 \mathrm{X} \\
5 \mathrm{Y} \\
6 \mathrm{P} \\
6 \mathrm{Q} \\
6 \mathrm{R} \\
6 \mathrm{~S} \\
6 \mathrm{~T} \\
6 \mathrm{U} \\
6 \mathrm{~V} \\
6 \mathrm{~W} \\
6 \mathrm{X} \\
6 \mathrm{Y} \\
7 \mathrm{P} \\
7 \mathrm{Q} \\
7 \mathrm{R} \\
7 \mathrm{~S} \\
7 \mathrm{~T} \\
7 \mathrm{U} \\
7 \mathrm{~V} \\
7 \mathrm{~W} \\
7 \mathrm{X} \\
7 \mathrm{Y} \\
8 \mathrm{P} \\
8 \mathrm{Q} \\
8 \mathrm{R} \\
8 \mathrm{~S} \\
8 \mathrm{~T}\end{array}$ & $\begin{array}{l}\text { F5 } \\
\text { F6 } \\
\text { F7 } \\
\text { F8 } \\
\text { F9 } \\
\text { G0 } \\
\text { GI } \\
\text { G2 } \\
\text { G3 } \\
\text { G4 } \\
\text { G5 } \\
\text { G6 } \\
\text { G7 } \\
\text { G8 } \\
\text { G9 } \\
\text { Ho } \\
\text { HI } \\
\text { H2 } \\
\text { H3 } \\
\text { H4 } \\
\text { H5 } \\
\text { H6 } \\
\text { H7 } \\
\text { H8 } \\
\text { H9 } \\
\text { Io } \\
\text { I1 } \\
\text { I2 } \\
\text { I3 } \\
\text { I4 }\end{array}$ & $\begin{array}{l}U_{5} \\
U_{6} \\
U_{7} \\
U_{8} \\
U_{9} \\
V_{0} \\
V_{1} \\
V_{2} \\
V_{3} \\
V_{4} \\
V_{5} \\
V_{6} \\
V_{7} \\
V_{8} \\
V_{9} \\
W_{0} \\
W_{1} \\
W_{2} \\
W_{3} \\
W_{4} \\
W_{5} \\
W_{6} \\
W_{7} \\
W_{8} \\
W_{9} \\
X_{0} \\
X_{1} \\
X_{2} \\
X_{3} \\
X_{4}\end{array}$ \\
\hline
\end{tabular}

The first part of the form provides for the entry of hospital, patient, and physician identification data. Clinical diagnosis and the catheter diagnosis can also be entered. These diagnostic entries have to be coded for the computer; these codes are the only ones not printed on the form, but space is available for the diagnosis to be written directly for ease of interpretation. The diagnostic codes (Table I) were specially developed so that the type, severity, and aetiology of most forms of congenital and acquired heart disease can be easily recorded. Details of sedation or of any anaesthetic technique can also be entered.

The section on 'procedure' (sheet 2) gives details of the mode of insertion of the catheter, vessels and cardiac chambers entered, the sites at which cine or serial film angiographic records were made, and the type and dose of contrast material used for these investigations. Thus simple right and left heart catheterization, with cine angiograms in the left ventricle and aorta, would be coded as shown in Fig. 5. Complications during cardiac catheterization are also coded very simply at the moment. If a significant complication rate is found, then a more comprehensive system, such as that described by Braunwald and Swan (1968), may be adopted in the future.

Results are entered on sheet 3. These are the values of blood pressure and oxygen saturation for that particular patient considered representative by the investigator. Elapsed time is also recorded so that the cardiologist can follow the time course of the investigation and interpret changes in oxygen saturation or pressure appropriately. The oxygen saturations or contents of blood samples suitable for calculating systemic and pulmonary blood flows are entered by the investigator at the bottom of sheet 3. Again he can use his own judgement in choosing values depending on the information available and the nature of the anatomical defect.

Sheet 4 is used for entering data about valve gradients, shunt flows and resistances, and the results of any determinations of cardiac output, which may be made by a variety of methods. The acid-base state of the patient can also be recorded if necessary. Results are entered by the investigator on this sheet, as they may be needed before the computer print-out is available. Mathematically the calculations are relatively trivial, but may be duplicated by the computer as part of the error checking system. Additional copies of sheets 3 and 4 may be used as often as required in any individual study to allow information to be entered following any of the interventions listed at the top of sheet 3. For instance, the effects of exercise, $\beta$-blockade, or oxygen inhalation 
PROCEDURE

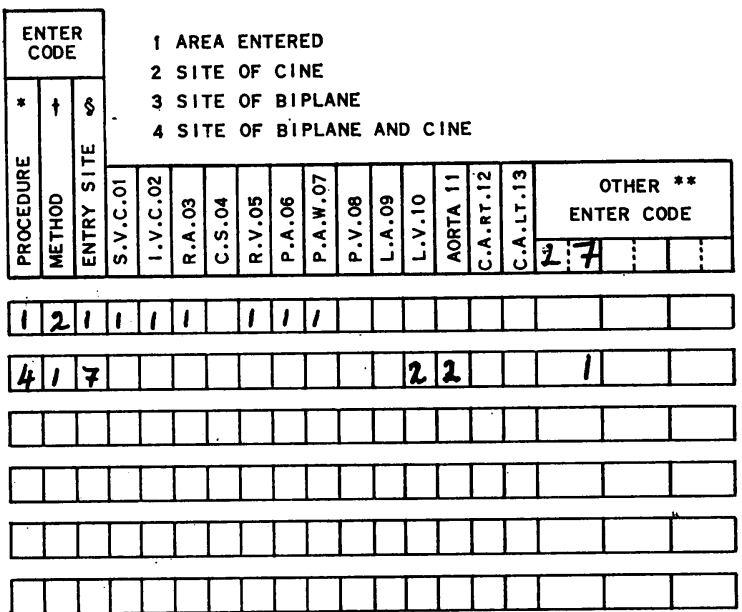

\section{X-RAY PARTICULARS}

\begin{tabular}{|c|c|c|c|c|c|c|c|c|}
\hline \multirow{2}{*}{ 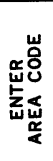 } & \multicolumn{2}{|c|}{$\begin{array}{l}\text { CONTRAST } \\
\text { MEDIUM } \\
\text { tit }\end{array}$} & \multirow{2}{*}{ } & \multicolumn{2}{|c|}{\begin{tabular}{|c|} 
CONTRAST \\
MEDIUM \\
\end{tabular}} & \multirow{2}{*}{ 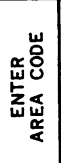 } & \multicolumn{2}{|c|}{$\begin{array}{c}\text { CONTRAST } \\
\text { MED IUM } \\
+t\end{array}$} \\
\hline & $\sum^{\frac{\omega}{2}}$ & 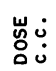 & & 嵅 & نे & & 15 & 岁。 \\
\hline
\end{tabular}
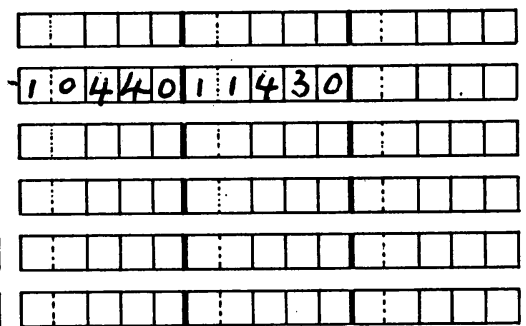

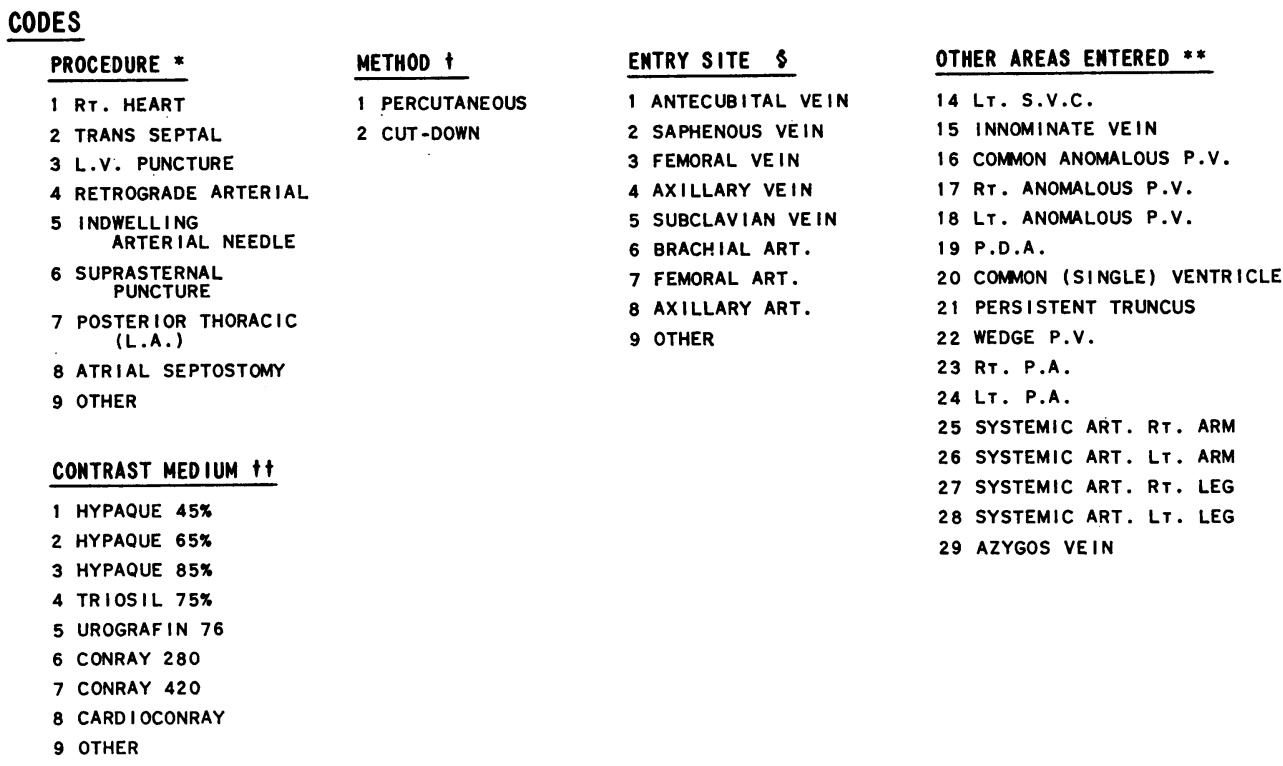

FIG. 5. Part of sheet 2, showing coding for simple right and left heart catheterization, with cineangiograms in left ventricle and aorta.

may be separately investigated and the results entered on the appropriate data sheets. A readily interpretable print-out suitable for inclusion in the patient's notes is obtained in standard format as shown in Fig. 6. Automatic error checking is not provided in the computer programme at the present time, but information in the data store on magnetic tape can be corrected if and when errors are detected on the print-out.

\section{Results}

The system has now been in operation since January 1970. A number of London hospitals have been associated with the scheme, namely the
Brompton Hospital, Guy's Hospital, the London Chest Hospital, and Westminster Hospital. The Radcliffe Infirmary, Oxford, joined the group in 1973. The records of over I000 cases are now collected annually. Initially forms were processed on a weekly basis to provide catheter reports, but now a twice weekly service has been introduced. The data forms and computer print-out have proved acceptable at most of the hospitals associated with the scheme and have largely replaced other methods of recording results and producing reports. At Guy's Hospital however the pre-existing reporting methods 
The Brompton Hospital

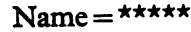

Date $=$ I5 Oct 1973

Height $=93 \mathrm{~cm}$

Cine no. $=$
Cardiac Catheterization Report No. 7307

Sex $=$ Male

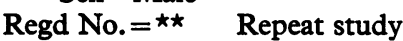

Weight $=12.9 \mathrm{~kg} \quad$ Surface area $=0.57 \mathrm{~m}^{2}$

Clinical diagnosis

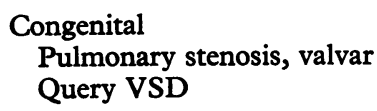

Catheter diagnosis

Congenital

Laevo-transposition

VSD

Pulmonary stenosis, infundibular

Visceral situs-solitus

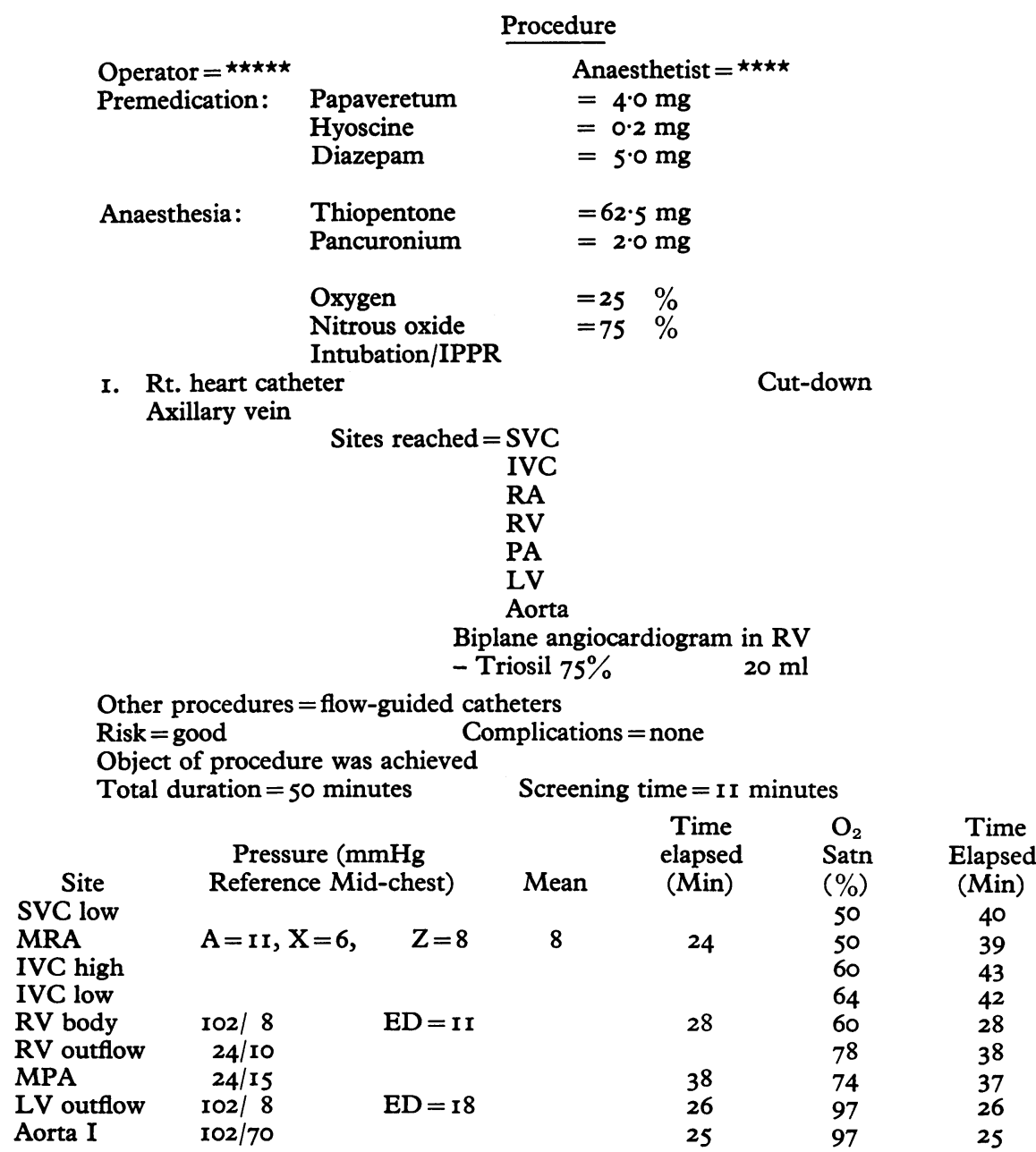

FIG. 6 Computer print-out of cardiac catheterization report (retyped). [continued opposite.] 
were retained and the computer system operated in parallel. The increased work load proved unacceptable to the investigators concerned, and Guy's Hospital left the group after the system had been in operation for about 18 months.

During the period 1970 to 1973 , records of 5200 cases have been coded. Details of the aetiology of the lesions found at cardiac catheterization are shown in Table 2. Postoperative studies have been included separately as these are invariably repeat investigations. There has been a progressive increase in the number of cases of arteriosclerotic (coronary) heart disease investigated. Cases where the aetiology was unrecorded rose dramatically in 1973. This is probably because the number of cardiologists using the system has increased and many of them were not associated with the original design of the data entry form.

TABLE 2 Numbers of patients in various aetiological groups since beginning of study: some had more than one aetiological diagnosis

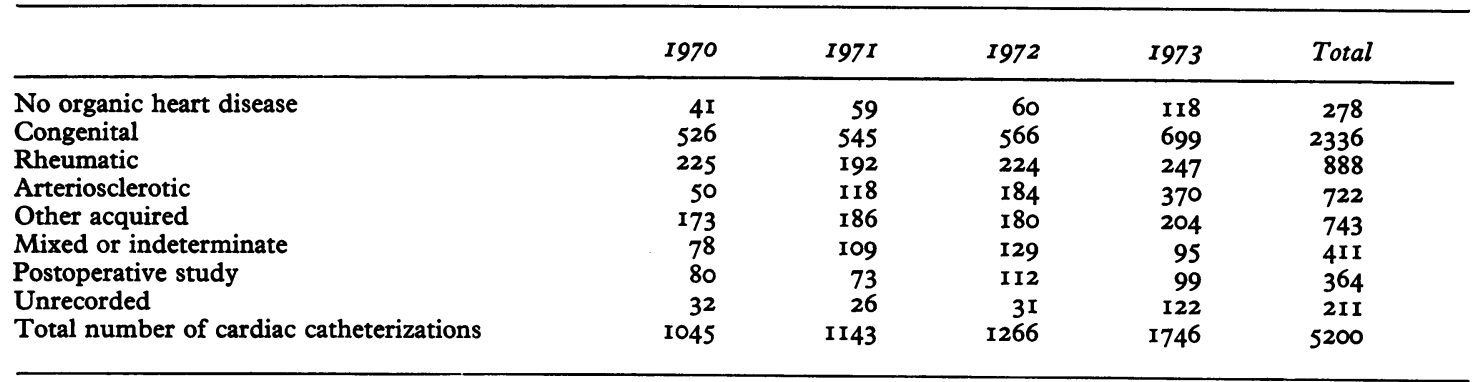

Data for flow calculations

Systemic (mixed) venous

Systemic arterial

Pulmonary venous

Pulmonary arterial

Flow measured by Fick principle

Oxygen saturation measured by oximetry

Oxygen consumption $=208 \mathrm{ml} / \mathrm{min}$ per $\mathrm{m}^{2}$ (assumed basal)

Haemoglobin $=10.2 \mathrm{~g} / 100 \mathrm{ml}$

Oxygen capacity $=14 \cdot 1 \mathrm{ml} / \mathrm{I00} \mathrm{ml}$

Systemic flow (QS)

Pulmonary/systemic flow ratio (QP/QS)

Total pulmonary resistance (RP)

Left-to-right shunt

\section{Saturation (\%)}

58

97

97

74

Calculations

$=5.81 . / \mathrm{min}$ per $\mathrm{m}^{2}$

$=3.51 . / \mathrm{min}$ per $\mathrm{m}^{2}$

$=3 \cdot 1$ units $\times \mathrm{m}^{2}$

$=2 \cdot 3 \mathrm{l} . / \mathrm{min}$ per $\mathrm{m}^{2}$
Content $(\mathrm{ml} / \mathrm{roO} \mathrm{ml})$

$8 \cdot 2$

14.0

$14 \cdot 0$

10.4

Peak gradient

pulmonary valve $\quad 78 \mathrm{mmHg}$ 


\section{Discussion}

In addition to providing a routine cardiac catheterization reporting system, the data bank can be used as a sophisticated card index and each hospital receives quarterly summaries of all cardiac catheterizations and an annual report. Lists of patients with a particular diagnosis or those catheterized in given age groups can be readily retrieved. Multiple correlations can also be performed, so that, for example, the effects of anaesthesia or the relation between age, procedure, and complication rate, can be established. A paper comparing the formulae used to estimate the oxygen saturation of mixed venous blood from vena caval samples (Miller, Brown, and Miller, 1974) illustrates one way in which the system has been used.

It is proposed to extend the system so that the catheter findings can be correlated with the surgical procedure, postoperative course, and long-term results of surgery.

\section{References}

Braunwald, E., and Swan, H. J. C. (1968). Co-operative study on cardiac catheterization. Circulation, 37, Suppl. 3.

Henry, W. L., Crouse, L., Stenson, R., and Harrison, D. C. (1968). Computer analysis of cardiac catheterization data. American fournal of Cardiology, 22, 696.

Miller, H. C., Brown, D. J., and Miller, G. A. H. (1974). Comparison of formulae used to estimate oxygen saturation of mixed venous blood from caval samples. British Heart fournal, 36, 446.

Wallace, A. G., and Rosati, R. A. (1973). Computers can change cardiology. Circulation, 47, 439.

Requests for reprints to Dr. J. P. Blackburn, Department of Clinical Measurement, Westminster Hospital, London S. W. I. 